\title{
El Concilio Vaticano II y el estudio sistemático de la Teología
}

Antes de hablar del estudio de la Teología desde la perspectiva del Concilio Vaticano II, permitan una aproximación anecdótica y, al mismo tiempo, de fondo. Se necesita un cierto valor para concebir un libro como el que a finales de los años sesenta del siglo pasado, con la reciente celebración del concilio Vaticano II al fondo, planeara José María Gironella, «100 españoles y Dios». Preguntar a cien españoles conocidos, famosos, algunos de renombre mundial -científicos, artistas, filósofos, novelistas, cantantes, pintores, políticos, etc.-, si creen en Dios, si creen que Cristo es Dios, si creen en otra vida, etc., y conseguir que respondan y contesten con sinceridad a estas preguntas íntimas, no es una empresa fácil. Un texto así nos introduce en los temas medulares de la Teología. Pero anecdótica resulta, por estrafalaria, la respuesta que Salvador Dalí daba a otra de las preguntas de la encuesta: ¿Cree usted que el Concilio Vaticano II ha sido eficaz? El genio de Cadaqués comentaba: "Íntimamente no soy partidario del Concilio, pero por razones propias de mi estructura jesuítica lo defiendo".

No tanto por razones de mi estructura jesuítica, sino por haber dedicado unas cuantas horas de estudio a la 21 asamblea ecuménica de la Iglesia católica me atrevo a proponer unas reflexiones fragmentarias sobre el estudio de la Teología sistemática. Hace ya algunos años los decanos de Teología de España y Portugal fueron consensuando unos planes de estudios bastante convergentes. Que esto fuera posible, se debe seguramente al hecho de que se puede detectar una síntesis doctrinal que presta su inspiración a los mismos documentos conciliares. En su día, el P. A. Antón presentó la eclesiología como nuevo centro de perspectiva en el estudio de la Teología, pues no en vano, y se juzgue como se juzgue, el Vaticano II ha sido "el concilio de la Iglesia sobre la Iglesia", según la fórmula casi tautológica acuñada por K. Rahner². Ahora bien, si el tema eclesiológico había impreg-

\footnotetext{
1 José María Gironella, 100 españoles y Dios, Barcelona 1969, 180.

2 A. ANTón, El tratado "De Ecclesia" nuevo centro de perspectiva en la enseñanza de la teología: Gregorianum 50 (1969) 651-687.
} 
nado toda la doctrina conciliar, sin embargo no se puede perder de vista el aspecto más hondo y perdurable del legado doctrinal del Concilio Vaticano II que consiste en proponer el misterio de Cristo como hilo conductor de la Teología.

Si las constituciones sobre la Iglesia, Lumen gentium, y sobre la revelación, Dei Verbum, configuran el centro de unidad de su reflexión teológica, su núcleo gira en torno al principio hermenéutico más genuino presente en la Teología de los Padres: centrar su reflexión en torno al mysterium Christi en las diversas etapas de su realización en la historia de la salvación. Mysterium Christi e historia salutis A la luz de una visión trinitaria de la historia de la salvación el misterio de Cristo se propone en ambas constituciones como la plenitud de la revelación y su continuación en la Iglesia en cuanto comunidad de creyentes, nacida de la escucha de la Palabra de Dios con el encargo de estar al servicio de esa Palabra, y celebrar los Sacramentos de la vida, haciendo presente el Evangelio de la salvación en el mundo hasta la consumación escatológica, conforme a las líneas maestras de la constitución sobre la liturgia, Sacrosanctum Concilium, y de la constitución pastoral Gaudium et spes, respectivamente. Esta perspectiva de fondo -mysterium salutis-sacramentum mundi- determina el puesto de los distintos tratados en el sistema de los estudios teológicos. Cualquier plan de estudios que quisiere ser fiel al espíritu y la letra del Concilio Vaticano II debe tomar en consideración estos postulados, sintetizados magistralmente en el título de la Relación Final del Sínodo extraordinario de Obispos (de 1985) que quiso conmemorar los veinte años de su clausura: La Iglesia (LG) a la escucha de la Palabra de Dios (DV) celebra los sacramentos (SC) para la salvación del mundo (GS).

El sistema teológico adolece -al igual que otras disciplinas científicasde un gran pluralismo de materias, problemas y métodos. Docentes y estudiantes se lamentan de que los planes de estudio están sobrecargados, al tiempo que se produce una cierta tendencia hacia la especialización. Al comienzo del curriculum theologicum se experimenta con más intensidad la tensión dialéctica de este pluralismo de materias y métodos. El principio hermenéutico citado -centrar la reflexión en torno al Mysterium Christi en toda su realización histórica- permite reorganizar las distintas disciplinas en torno a esa dimensión histórico-salvífica que da unidad a la Teología. Así se comprende el valor específico de las disciplinas de índole bíblica (Antiguo y Nuevo Testamento), en primer término, así como el apoyo que tanto la Teología fundamental como las materias históricas prestan al desarrollo de la teología sistemática que se debe proponer en el ciclo institucional básico de Teología. Recorramos entonces sus núcleos: 
1) Toda la economía de la revelación y salvación tiene en el misterio de Cristo su centro de unidad y punto de convergencia. Así las cosas, el tratado de Dios Uno y Trino y la Cristología perfilan el corazón de una perspectiva económica asentada sobre la centralidad del misterio de Dios manifestado en Cristo Jesús.

2) Un segundo círculo concéntrico hacia afuera, prolongando la historia de la salvación, nos sitúa ante el mysterium ecclesiae. La Iglesia es continuación del misterio de Cristo que se ha instalado en la historia humana, para ser pueblo de Dios, cuerpo de Cristo, templo del Espíritu Santo. El tratado de Eclesiología se sabe en profunda continuidad con la Pneumatología y con la Cristología, pues la Iglesia ha nacido de la doble experiencia de la Pascua y de Pentecostés. El Hijo y el Espíritu Santo son -en la terminología de S. Ireneo- las dos manos del Padre. En el despliegue histórico de la Iglesia, creatura Verbi y sacramentum salutis, se inscribe la vida de la institución eclesial, su interioridad litúrgica y su espiritualidad, su estructura canónica y las diversas formas de la única vocación cristiana, con la cristalización de un pensamiento teológico-moral, que se plasma también en una misión y en un compromiso social.

3) La Iglesia no tiene su origen en la simple intención del Jesús histórico, sino en todo el acontecimiento de Cristo; el misterio de la Iglesia converge en el misterio de la encarnación. En la sacramentalidad del misterio de Cristo se funda la sacramentalidad del misterio de la Iglesia. En esta perspectiva histórico-salvífica la sacramentalidad de la Iglesia es el fundamento de un tercer círculo concéntrico que comprende la teología de los sacramentos en su dimensión cristológica y eclesial. Cristo es el sacramento primordial del plan salvífico de Dios; los sacramentos son no sólo medios de gracia, sino actualizaciones de la obra salvadora de Cristo mediante su Espíritu, y al mismo tiempo, actuaciones y actualizaciones de toda la Iglesia. Cristo-Iglesia-sacramentos-virtudes: son los ejes que articulan el avance sistemático de la Teología.

4) El cuarto círculo concéntrico de este desarrollo sistemático de la Teología lo constituye la Antropología teológica: siendo Cristo el centro de unidad de esta visión teológica el plan de salvación comienza con la creación en Cristo; el hombre histórico se halla ya elevado al orden de la gracia, y la teología de la gracia tiene una dimensión cristológica y eclesial. Completando los artículos del Símbolo de fe, la perspectiva antropológica -con las cuestiones clásicas del pecado y de la justificación-, se deja prolongar en la teología de las realidades del más allá, la escatología cristiana, que introduce la dimensión humana de la muerte y el final absoluto de la humanidad en la parusía de Cristo como el evento consumador de la historia. 
Todavía habría que hablar de los métodos de estudio, al socaire de las disposiciones del decreto sobre formación sacerdotal, Optatam totius (1318), cuya intención última puede quizás sustanciarse en el triple ideal que presidió el esfuerzo de renovación teológica promovido por la Escuela de Tubinga: el principio de la eclesialidad, el carácter científico de la Teología, y su apertura a las cuestiones contemporáneas ${ }^{3}$. Efectivamente, el estudio de la teología, ayer, hoy, y siempre reclama una sutil alquimia que sepa aunar pietas, eruditio, iustitia. Quisiera concluir con dos reflexiones acerca de la naturaleza de la teología:

1. En primer lugar, recurriré a Martín Lutero. En 1518, cuando aún era fraile agustino escribió como ejercicio académico para la Controversia de Heidelberg aquellas tesis que han puesto las bases de la llamada teología de la cruz: "No puede llamarse en justicia teólogo al que crea que las cosas invisibles de Dios pueden aprehenderse a partir de lo creado... Sino, mejor a quien aprehende las cosas visibles e inferiores de Dios a partir de la pasión y de la cruz... de tal manera que no basta ni aprovecha a nadie el conocimiento de Dios en su gloria, si no se le conoce también en la humildad y en la ignominia de la cruz"4.

2. En Teología no se trata primariamente de lo que se dice de Dios, ni siquiera de lo que la fe dice de Él, sino de lo que Él mismo dice de sí en el momento que se manifiesta, y por tanto de Dios mismo. Me sirvo para concluir de las palabras añejas del místico S. Juan de la Cruz: "Y este es el deleite grande de este recuerdo: conocer por Dios las criaturas y no por las criaturas a Dios; conocer los efectos por su causa y no la causa por sus efectos, que es conocimiento trasero y esotro esencial" 5 . En suma: que la teología consista en pensar rigurosa, metódica, sistemáticamente, a Dios como es en sí y como salvador de todo, que Cristo es el Sí de Dios a la humanidad nuestra $(2$ Cor 1,19$)$, eso es lo que legitima y da grandeza a la Teología.

\section{SANTIAGO MADRIGAL, Decano de la Facultad de Teología de la Universidad Pontificia de Comillas}

\footnotetext{
${ }^{3}$ W. KASPER, «Situación y tareas actuales de la Teología sistemática», en: Teología e Iglesia, Barcelona 1989, 13ss.

${ }_{5}^{4}$ M. LuTERo, Obras, edición preparada por T. Egido, Salamanca 1977, 82.

5 Llama de amor viva, canción 4, n. 5, en: Obras completas, Madrid, 1989, 860.
} 